\title{
A NOÇÃO DE TRABALHO A TEMPO PARCIAL NO DIREITO ESPANHOL COMO UM INSTRUMENTO DA "FLEXISEGURANÇA"
}

\author{
THE NOTION OF PART-TIME LABOR IN SPANISH LAW AS \\ AN INSTRUMENT OF FLEXISEGURIDAD
}

\author{
GILBERTO STÜRMER ${ }^{1}$ \\ RODRIGO COIMBRA ${ }^{2}$
}

\begin{abstract}
RESUMO: O presente artigo visa discutir o contrato de trabalho a tempo parcial, enquanto instrumento da flexisegurança - pauta do momento na Comunidade Europeia - que objetiva conciliar a flexibilização dos direitos dos trabalhadores com a suposta segurança de que continuarão havendo empregos, ou, pelo menos, medidas de proteção para os desempregados, aliadas a uma política de recolocação no mercado de trabalho. Partindo-se da contextualização e de alguns precedentes da flexibilização dos direitos trabalhistas em alguns países da União Europeia e nos Estados Unidos da América, passa-se pelo estudo das Diretrizes da Comunidade Europeia sobre a matéria, desde o Acordo marco europeu em matéria de trabalho a tempo parcial reconhecido pela Diretiva 97/81/CE (1997), culminado com uma análise crítica do trabalho a tempo parcial no Direito Espanhol. PALAVRAS-CHAVE: Trabalho a Tempo Parcial; Flexibilização; "Flexiseguridad"; Comunidade Europeia; Direito Espanhol.
\end{abstract}

Artigo recebido em 21.04.2012. Pareceres emitidos em 04.09.2012 e 22.09.2012.

Artigo aceito para publicação em 19.11.2012.

${ }^{1}$ Doutor em Direito pela Universidade Federal de Santa Catarina, Florianópolis. Mestre em Direito pela Pontifícia Universidade Católica do Rio Grande do Sul, Porto Alegre (PUCRS). Professor de Direito do Trabalho e Direito Processual do Trabalho na PUCRS - Graduação, Especialização, Mestrado e Doutorado. Coordenador do Departamento de Direito Público e Social da Faculdade de Direito da PUCRS. Coordenador do Curso de Especialização em Direito e Processo do Trabalho da Faculdade de Direito da PUCRS. Coordenador e Pesquisador do Grupo de Pesquisa "Estado, Processo e Sindicalismo" do Programa de Pós-Graduação em Direito da PUCRS. Advogado.gsturmer@sturmer.com.br

${ }^{2}$ Doutorando em Direito pela Pontifícia Universidade Católica do Rio Grande do Sul, Porto Alegre (PUCRS). Mestre em Direito pela Universidade Federal do Rio Grande do Sul, Porto Alegre. Professor de Direito do Trabalho e Direito Processual do Trabalho da Graduação e Pós-Graduação da Universidade FEEVALE, Novo Hamburgo-RS e dos Cursos de Pós-Graduação dessas áreas na PUCRS, IMED Porto Alegre, RS; Centro Universitário Ritter dos Reis - UniRitter, Canoas e Porto Alegre, RS; e Universidade de Santa Cruz do Sul, Santa Cruz do Sul, RS. Advogado. rodrigo.coimbra@terra.com.br 
ABSTRACT: This article aims to discuss the contract of part-time work as an instrument of flexicurity - the agenda of the moment in the European Community which aims to combine the flexibility of labor rights with the supposed security that will continue having jobs, or at least measures protection for the unemployed, coupled with a policy of replacement labor market. Based on the foregoing and the contextualization of flexibility of labor rights in some countries of the European Union and the United States, shall be the study of the European Community Guidelines on the matter, since the European Framework Agreement on work part time recognized by Directive 97/81/EC (1997), culminating in a critical analysis of part-time work in Spanish law.

KEYWORDS: Part-time Work; Flexibility; "Flexecurity"; European Community; Spanish Law.

SUMÁRIO: Introdução; 1. Contexto e Alguns Precedentes da Flexibilização dos Direitos Trabalhistas; 2 . O Trabalho a Tempo Parcial como Instrumento de Política de Emprego da Comunidade Europeia e Estratégia de Flexisegurança; 3. O Acordo Marco Europeu em Matéria de Trabalho a Tempo Parcial reconhecido pela Diretiva 97/81/CE (1997) - Definições e Princípios; 4. A Noção de Trabalho a Tempo Parcial no Direito Espanhol - Análise Crítica; Considerações Finais; Referências.

SUMMARY: Introduction; 1. Context and Some Unprecedented Flexibility of Labor Rights; 2. The part-time Work as an Instrument of Employment Policy of the European Community Strategy "flexecurity"; 3 . The March European Agreement on Part-time Work recognized by Directive 97/81/EC (1997) - Definitions and Principles; 4. The Notion of Part-time Workin Spanish Law - Critical Analysis; Final Considerations; References.

\section{INTRODUÇÃO}

A modalidade de contratação de trabalho a tempo parcial, enquanto instrumento da sempre polêmica, mas inarredável "flexicurity" ("flexiseguridad" ou "flexisegurança") - segundo a tradução literal do termo originário em língua inglesa para o castelhano ou para o português -, tem sido muito utilizada na União Europeia nos últimos vinte anos, tendo aumentado a sua importância notadamente após a crise econômica de 2008-2012, também chamada de grande recessão ou crise dos subprimes ${ }^{3}$, iniciada nos Estados Unidos da

\footnotetext{
${ }^{3}$ A crise econômica de 2008-2012, também chamada de Grande Recessão, "é um desdobramento da crise financeira internacional precipitada pela falência do tradicional banco de investimento estadunidense Lehman Brothers, fundado em 1850. Em efeito dominó, outras grandes instituições financeiras quebraram, no processo também conhecido como 'crise dos subprimes'. Alguns economistas, no entanto, consideram que a crise dos subprimes tem sua causa primeira no estouro da 'bolha da Internet' (em inglês, dot-com bubble), em 2001, quando o índice Nasdaq (que mede a variação de preço das ações de empresas de informática e telecomunicações) despencou. De todo modo, a quebra do Lehman Brothers foi seguida, no espaço de poucos dias, pela falência técnica da maior empresa seguradora dos Estados Unidos da América, a American International Group (AIG). O governo norte-americano, que se recusou a oferecer garantias para que o banco inglês Barclays adquirisse o controle do cambaleante Lehman Brothers, alarmado com o efeito sistêmico que a falência dessa tradicional e poderosa instituição financeira abandonada às 'soluções de mercado' - provocou nos mercados financeiros mundiais, resolveu, em vinte e quatro horas, injetar oitenta e cinco bilhões de dólares de dinheiro público na AIG para salvar suas operações. Mas, em poucas semanas, a crise norte-americana já atravessava o Atlântico" (pt.wikipedia.org.<http://pt.wikipedia.org/wiki/Crise_econ\%C3\%B4mica_de_2008-2012>. Acesso em 24 mar. 2012).
} 
América, que, em efeito dominó, afetou significativamente alguns países da Comunidade Europeia, dentre os quais a Espanha onde a situação é uma das mais graves nesse particular.

Dados da última Pesquisa Força de Trabalho revelam que a taxa de desemprego é de 5.273 .600 pessoas, um aumento de 295.300 no quarto trimestre de 2011 e 577.000 no quarto trimestre de 2010. ${ }^{4}$ A taxa de desemprego na Espanha bateu novo recorde recentemente chegando a $24,3 \%$. O número de desempregados chegou a 4,7 milhões em fevereiro de 2012 - o índice mais elevado entre as nações industrializadas, segundo o Instituto Nacional da Estatística da Espanha. ${ }^{5}$ Esse panorâma demonstra a importância, a atualidade e a justificativa de estudo desse tema.

Conforme estudo de Rodríguez ${ }^{6}$ o trabalho a tempo parcial passou de $13 \%$ a $18 \%$ do emprego total da União Europeia entre 1990 e 2005 e desde 2000 representa aproximadamente $60 \%$ dos empregos, sendo que $1 / 3$ das mulheres estão empregadas nessa modalidade (homens - 7\%).

Pretende-se, no presente artigo, a partir desse contexto, trazer a lume precedentes da flexibilização dos direitos trabalhistas em alguns países da União Europeia e nos Estados Unidos da América, após analisar as Diretrizes da Comunidade Europeia sobre a matéria - a partir do Acordo marco europeu em matéria de trabalho a tempo parcial reconhecido pela Diretiva 97/81/CE (1997) -, culminado com uma análise crítica do trabalho a tempo parcial no Direito Espanhol.

Como método científico de abordagem do assunto será utilizado o método dedutivo, que é aquele cujo antecedente é constituído de princípios universais, plenamente inteligíveis, do qual se chega a um consequente menos universal, inferir e concluir ao final. ${ }^{7}$

A abordagem da pesquisa se dará pelo modelo qualitativo na medida em que se buscará o entendimento do fenômeno em seu próprio contexto. ${ }^{8}$

\section{CONTEXTO E ALGUNS PRECEDENTES DA FLEXIBILIZAÇÃO DOS DIREITOS TRABALHISTAS}

Nos anos 1980 e 1990 importantes países da Europa e os Estados Unidos da América tomaram uma série de medidas que revigoraram o liberalismo econômico, o que ficou conhecido como "neoliberalismo", norteado pela

\footnotetext{
${ }^{4}$ Esses dados, e outros tantos, constam na exposição de motivos do Real Decreto-ley 3/2012.

${ }^{5}$ Notícia de 03.03.2012. www.portugues.rfi.fr.<http://www.portugues.rfi.fr/europa/20120302-espanhataxa-de-desemprego-bate-novo-recorde-e-chega-243>. Acesso em 20 mar. 2012.

6 RODRÍGUEZ, Jesús Baz. El Marco Jurídico Comunitário del Trabajo a Tiempo Parcial. Reflexiones em el Contexto de la "flexiseguridad". In: Trabajo a Tiempo Parcial y Flexiseguridad. RODRÍGUEZ, Jesús Baz (Org.). Granada: Comares, 2008, p. 9.

${ }^{7}$ FINCATO, Denise Pires. A Pesquisa Jurídica sem Mistérios: do projeto de pesquisa à banca. Porto Alegre: Notadez, 2008, p. 38.

${ }^{8}$ MEZZAROBA, Orides; MONTEIRO, Cláudia Servilha. Manual de Metodologia da Pesquisa no Direito. 3. ed., São Paulo: Saraiva, 2006, p. 110.
} 
concepção de pouca intervenção do Estado na economia e nas relações de trabalho.

Essa significativa retomada das ideias liberais $^{9}$ começou nos governos de Margareth Thatcher na Inglaterra (1979-1990) e de Ronald Reagan nos Estados Unidos (1980-1988). Nos EUA houve uma variação no modelo, pois sempre foram mais liberais e menos regulamentadores que os países Europeus, conquanto seja possível destacar algumas semelhanças entre as principais reformas neoliberais praticadas por estes países: contraíram a emissão monetária, produzindo valorização da moeda e também um efeito potencialmente recessivo; baixaram consideravelmente os impostos, principalmente sobre as grandes empresas; enfrentaram greves; criaram uma legislação anti-sindical; e, cortaram gastos sociais. ${ }^{10}$ Depois se seguiu um programa de privatização. ${ }^{11}$

Nesta esteira, a Alemanha (Helmut Kohl 1982-1998), a Espanha (reformas de 1994) e a Itália (reformas dos anos 1990), seguiram a ordem econômica internacional promovendo reformas de cunho neoliberais. ${ }^{12}$

Gerard Lyon-Caen explica de forma direta a geração da onda neoliberal no direito do trabalho: "o sistema de relações profissionais, ligado ao forte poder da organização sindical foi progressivamente destruído no curso da era Thatcher. A desregulamentação virou moda". ${ }^{13}$

Nesse cenário, o desenvolvimento do processo de internacionalização do capital define o que se chama de globalização da economia, que constitui um novo cenário para a década de 1990 e seguintes, tendo importantes reflexos no Direito do Trabalho.

A globalização, ou "os processos de globalização", na expressão que dá maior dinâmica a este fenômeno que segue em andamento nos dias atuais cunhada por Boaventura de Souza Santos ${ }^{14}$, é um tema que tem adquirido

\footnotetext{
${ }^{9}$ CATHARINO chama essa retomada de "o rebrote da doutrina liberal" (CATHARINO, José Martins. El Rebrote de Ladoctrina Liberal y los Modelos Flexibilizadores. In: Evolucion del Pensamento Juslaboralista. Montevideo: Fundacion de Cultura Universitária, 1997, p. 103-122).

${ }^{10}$ COIMBRA, Rodrigo; ARAÚJO, Francisco Rossal de. Direito do Trabalho: evolução do modelo normativo e tendências atuais na Europa. Revista LTr. São Paulo: LTr, ano 73, nº 08, p. 960, ago. 2009.

${ }^{11}$ Para um detalhamento dos problemas estruturais das relações industriais européias na década de 80 ver BAGLIONI, Guido. O Mundo do Trabalho - Crise e mudança no final do século. São Paulo: Scritta, 1994, p. 54-58.

${ }^{12}$ COIMBRA, Rodrigo; ARAÚJO, Francisco Rossal de. Direito do Trabalho: evolução do modelo normativo e tendências atuais na Europa. Revista LTr. São Paulo: LTr, ano 73, nº 08, p. 960, ago. 2009.

${ }_{13}$ LYON-CAEN, Gerard. Derecho del Trabajo o Derecho del Emprego?. In: Evolución del Pensamento Juslaboralista. Montevideo: Fundacion de Cultura Universitária, 1997, p. 267.

${ }^{14}$ SANTOS, Boaventura de Souza. Os Processos de Globalização. In: A Globalização e as Ciências Sociais. SANTOS, Boaventura de Souza (Org.). 3. ed., São Paulo: Cortez, 2005, p. 25; André-Noel Roth sustenta que uma das principais causas, se não for a principal, da crise do Estado, cujos mecanismos econômicos sociais e jurídicos de regulação, postos há um mais de um século, já não funcionam, encontra-se no fenômeno da globalização. Salienta que essa
} 
grande importância, sobretudo nas últimas décadas, tendo se caracterizado mais recentemente por um fenômeno multifacetado com dimensões econômicas, sociais, políticas, culturais e jurídicas interligadas de modo complexo.

Esclarece o sociólogo português, que a globalização das últimas três décadas, em vez de encaixar no padrão moderno ocidental de globalização, parece combinar a universalização e a eliminação das fronteiras nacionais, por um lado, o particularismo, da diversidade local; a identidade étnica e o regresso ao comunitarismo, por outro. ${ }^{15}$

Impulsionada por elementos econômicos e por fatores políticos neoliberais, a globalização tem reclamado um dos ajustes estruturais mais selvagens da historia, de acordo com Rodolfo Capón Filas ${ }^{16}$, uma vez tem modificado toda a ordem econômica e social, gerando o deslocamento do trabalho: desemprego crescente em alguns países e aumento de postos de trabalho em outros; precarização de trabalho; deterioração da qualidade de vida; entre outros reflexos, como o crescimento da dívida externa nos países periféricos.

A partir da queda do muro do Berlin, em 09.11.1989 (existente desde 13.08.1961), tem-se um novo ciclo da globalização, que, vale lembrar não é algo novo, conquanto tenha sido retomada com novos moldes. Assim, como o Direito do Trabalho não surgiu na revolução industrial, que foi na célebre expressão de Segadas Viana ${ }^{17}$, a "fermentação" que daria origem ao surgimento das posteriores normatizações iniciais tutelando as relações de trabalho de forma lenta e gradual, a "fermentação" ou o marco simbólico inicial impulsionador do fenômeno denominado de globalização - cuja efetivação nos moldes atuais se dá por volta dos anos 2000 - foi a queda do muro de Berlim, que marca o final da guerra fria e a superação do conflito ideológico, de dimensão universal. Foi um momento histórico e de grande impacto. ${ }^{18}$

No entanto, a queda do muro de Berlin não contribuiu apenas para o achatamento das alternativas ao capitalismo de livre mercado e a libertação de gigantescas reservas reprimidas de energia de centenas de milhões de

interdependência dos Estados influi sempre mais na definição das políticas públicas internas de cada Estado. O autor chama atenção que o desenvolvimento das forças econômicas a um nível planetário diminui o poder de coação dos Estados nacionais sobre estas. Adverte, ainda, que o Estado está limitado em suas políticas fiscais e intervencionistas, em termos de alcance interno, pelas coações da competência econômica mundial. ROTH, André-Noel. O Direito em crise: fim do Estado moderno. In: Direito e Globalização Econômica: implicações e perspectivas. José Eduardo Faria (Org.). São Paulo: Malheiros, 1998, p. 17-18 e 26.

${ }^{15}$ SANTOS, Boaventura de Souza. Os Processos de Globalização. In: A Globalização e as Ciências Sociais. SANTOS, Boaventura de Souza (Org.). 3. ed., São Paulo: Cortez, 2005, p. 26.

${ }^{16}$ FILAS, Rodolfo Capón. Trabajo y Globalizacion propuesta para una praxis popular alternativa. Justiça do Trabalho. Porto Alegre: HS Editora, ano 18, $\mathrm{n}^{0}$ 205, jan. 2001, p. 10.

${ }_{17}$ SUSSEKIND, Arnaldo. et al. Instituições de Direito do Trabalho. V. 1. 20. ed., São Paulo: LTr, 2002, p. 41.

${ }^{18}$ FRIEDMAN, Thomas L. O Mundo é Plano: o mundo globalizado no século XXI. 3. ed., Rio de Janeiro: Objetiva, 2009, p. 66-69; Nesse sentido, no âmbito do Direito do Trabalho ver: SUSSEKIND, Arnaldo. A Globalização da Economia e o Direito do Trabalho. Revista LTr. São Paulo: LTr, v. 61, jan. 1997, p. 40. 
pessoas de lugares como Índia, Brasil, China e o antigo Império Soviético: permitiu-nos encarar o mundo como um todo de uma nova forma, vendo-o como uma unidade mais homogênea. Enfatiza Thomas Friedman que "o muro não somente bloqueava a passagem, como também a visão, isto é, nossa capacidade de ver o mundo como um único mercado, um só ecossistema, uma mesma comunidade". ${ }^{19}$

Nesse quadro, explica Romita que no mundo desenvolvido e em vias de desenvolvimento ocorreu, nos últimos vinte e cinco anos, uma verdadeira revolução científico-tecnológica, que deflagrou um processo de globalização em escala e em intensidade sem precedentes. Esse processo, que é irreversível, permite o deslocamento rápido, barato e maciço de mercadorias, serviços, capitais e trabalhadores. Grandes mercados regionais se tornaram possíveis e pode-se pensar, num futuro próximo, no surgimento de um único mercado planetário de bens e de trabalho. ${ }^{20}$

Juntamente com a globalização, também merecem destaque nessa época os movimentos de flexibilização de direitos trabalhistas, que exigem das empresas melhores níveis de competitividade, levando ao uso de novas técnicas de organização da produção e demandas de flexibilização dos direitos trabalhistas. ${ }^{21}$

\footnotetext{
${ }^{19}$ FRIEDMAN, Thomas L. O Mundo é Plano: o mundo globalizado no século XXI. 3. ed., Rio de Janeiro: Objetiva, 2009, p. 69; Para uma visão européia da globalização ver DE MASI, Domenico. O Futuro do Trabalho: fadiga e ócio na sociedade pós industrial. 5. ed., Brasília: Unb, 2000, 147-155; Conforme a concepção de Friedman $^{19}$ a plataforma do mundo plano é produto de uma convergência entre: a) o computador pessoal, que subitamente permitiu a cada indivíduo tornar-se autor de seu próprio conteúdo digital; b) o cabo de fibra ótica, que viabilizou tais indivíduos de acessar cada vez mais conteúdo digital no mundo, por quase nada; c) o aumento de softwares de trabalho, que possibilitou aos indivíduos, de todo o mundo, se relacionar e colaborar com esse conteúdo digital em muito aumentado, estando em qualquer lugar, independente da distância entre eles ${ }^{19}$. Essa convergência e democratização das tecnologias estão formando o que se chama de sociedade global ou sociedade da informação e evidenciam uma nova ordem econômica mundial, importante, complexa e inevitável. O autor esclarece que ninguém previu essa convergência, ela simplesmente aconteceu por volta dos anos 2000 (FRIEDMAN, Thomas L. O Mundo é Plano: o mundo globalizado no século XXI. 3. ed., Rio de Janeiro: Objetiva, 2009, p. 22).

${ }^{20}$ ROMITA, Arion Saião. Globalização da Economia e Direito do Trabalho. São Paulo: LTr, 1997, p. 28; sobre essa matéria ver também: SUSSEKIND, Arnaldo. A Globalização da Economia e o Direito do Trabalho. Revista LTr, São Paulo, v. 61, no 1, p. 41-44, jan. 1997; REALE, Miguel. A Globalização da Economia e o Direito do Trabalho, Revista LTr, São Paulo, v. 61, nº 1, jan. 1997, p. 11-13.

${ }_{21}$ LYON-CAEN, Gerard. Derecho del Trabajo o Derecho del Emprego?. In: Evolución del Pensamento Juslaboralista. Montevideo: Fundacion de Cultura Universitária, 1997, p. 267; CATHARINO, José Martins. El Rebrote de la Doctrina Liberal y los Modelos Flexibilizadores. In: Evolucion del Pensamento Juslaboralista. Montevideo: Fundacion de Cultura Universitária, 1997, p. 103-121; VÁSQUEZ, Jorge Rendón. El Caráter Protector del Derecho del Trabajo y la Flexibilidad com Ideologias. In: Evolucion del Pensamento Juslaboralista. Montevideo: Fundacion de Cultura Universitária, 1997, p. 419-430; VAN DER LAAT, Benardo. Limites a la Flexibildad: algunas situaciones que se han dado em Costa Rica. In: Evolucion del Pensamento Juslaboralista. Montevideo: Fundacion de Cultura Universitária, 1997, p. 501-510; ERRAZURIZ, Francisco Walker. La Flexibildad Laboral y los Princípios Orientadores del Derecho del Trabajo, teniendo em cuenta, em forma particular, algunos aspectos de la Legislación Chilena. In: Evolucion del Pensamento Juslaboralista. Montevideo: Fundacion de Cultura Universitária, 1997, p. 599-620.
} 
A flexisegurança é assunto do dia na União Europeia atualmente e pretende conciliar dois valores sensivelmente antagônicos, quais sejam a flexibilidade do mercado de trabalho e a segurança dos trabalhadores contra o desemprego. Essa conciliação ou ao menos uma maior aproximação se faz necessária e já é clamada expressamente desde a edição do "Livro Verde sobre Relações Laborais da União Européia", editado em novembro de 2006, que propugna pela "modernização do Direito do Trabalho para fazer frente ao desafio do século XXI". Nesse quadro, a Diretiva $n^{\circ} 21$ da União Européia objetiva "promover a flexibilidade combinada com segurança".

Esse é o significado do neologismo "flexisegurança", inspirado nos exemplos da Dinamarca (principalmente), Holanda e Suécia: promover a flexibilização dos direitos dos trabalhadores, sem retirar os direitos trabalhistas (geralmente constitucionalizados) conquistados pelos países membros da Comunidade Europeia.

Esse conceito procura aproximar às necessidades dos empregadores, mediante modalidades de contratação diferentes das tradicionais (por isso chamadas de atípicas), à necessidade fundamental da existência de empregos, em condições não menos favoráveis.

Sobre a busca da flexisegurança na Comunidade Europeia destaca-se três aspectos essenciais: a) a flexibilidade passa a ser uma exigência quase universal em ambientes industrializados e um dos problemas dominantes nos países europeus; b) a exigência expressa pelos empresários encontrou consensos mesmo fora dos seus âmbitos, principalmente por parte dos poderes públicos; c) a flexibilidade envolve, in totum, os conteúdos tradicionais, as regras das relações industriais e, portanto, a atuação sindical das empresas, na medida em que esta atuação representa a capacidade das empresas se reorganizarem em prazos curtos diante das flutuações da macroeconomia em um contexto geral já caracterizado por profundas incertezas e crescente competitividade ${ }^{22}$.

Essas necessidades referem-se tanto a flexibilidade interna (mudanças na organização do trabalho, administração dos horários, modalidades das tarefas e evolução das responsabilidades, sistemas retributivos), quanto à flexibilidade externa (variações do número de funcionários, contratos atípicos e anormais, mobilidade). ${ }^{23}$

Formas novas e atípicas de contratação, redistribuição do tempo e do trabalho (aqui entra o trabalho a tempo parcial), liberdade de supressão de empregos no caso de reestruturação, resumem as medidas tomadas no conjunto dos países europeus. Todas elas expressam a busca de uma redução do custo do trabalho e permitiram aos grupos europeus enfrentar a

\footnotetext{
${ }^{22}$ BAGLIONI, Guido. O Mundo do Trabalho - Crise e mudança no final do século. São Paulo: Scritta, 1994, p. 61-62.

${ }^{23}$ Para um relato da busca da flexibilidade nos países europeus, separadamente, ver BAGLIONI, Guido. O Mundo do Trabalho - Crise e mudança no final do século. São Paulo: Scritta, 1994.
} 
Ásia e os Estados Unidos, mas ao preço de uma insegurança e de um empobrecimento, que excluíram da tutela do Direito do Trabalho frações inteiras da população. ${ }^{24}$

Analisando o renovado debate Europeu em torno da "flexisegurança" e suas medidas, José Affonso Dallegrave Neto ${ }^{25}$ faz a seguinte apreciação crítica:

\begin{abstract}
"De uma análise fria e sem romantismo, chega-se a inferência de que se trata de mais uma medida em sintonia com a ideologia neoliberal, vez que os objetivos são claros: facilitar a vida da iniciativa privada em detrimento das condições de trabalho que se tornarão mais precárias em face da política de flexibilidade em seus diversos aspectos: contratação temporária; dispensa sem ônus; modalidades de salário vinculadas ao resultado; fixação de horários flexíveis visando atender exclusivamente a demanda da produção".
\end{abstract}

A "flexisegurança" parece estar mais focada com a "flexi" do que com a "segurança". Nos momentos de altas taxas de desemprego as ideias normalmente se resumem a sugerir a flexibilização das normas trabalhistas e o endividamento do Estado com aumento de quotas de Seguro-Desemprego. Poucas vezes se dirige o foco principal se dirige ao aquecimento da economia por meio do aumento da oferta de crédito pessoal com juros baixos e da elevação do consumo aliada a uma política de desoneração previdenciária da folha de pagamento.

\title{
2. O TRABALHO A TEMPO PARCIAL COMO INSTRUMENTO DE POLÍTICA DE EMPREGO DA COMUNIDADE EUROPEIA E ESTRATÉGIA DE FLEXISEGURANÇA
}

O tratado de Amsterdã (1997) ensaiou o método de coordenação das políticas trabalhistas estatais a cargo das instituições comunitárias em matéria de emprego, substancializado no denominado Livro Verde (2006), cujo lema era "modernizar o Direito do Trabalho face aos desafios do século XXI", tendo maior efetividade a partir das diretrizes para as políticas de emprego dos Estados Membros (2005-2008).

A promoção da flexibilidade combinada com a segurança do emprego, na ordem da redução da segmentação do mercado de trabalho, postula, entre outras ações, a revisão das diferentes modalidades contratuais e das disposições relativas ao tempo de trabalho, de acordo com Rodríguez. ${ }^{26}$

\footnotetext{
${ }^{24}$ LYON-CAEN, Gerard. Derecho del Trabajo o Derecho del Emprego?. In: Evolución del Pensamento Juslaboralista. Montevideo: Fundación de Cultura Universitária, 1997, p. 268.

${ }^{25}$ DALLEGRAVE NETO, José Affonso. Flexisegurança nas Relações de Trabalho. O novo debate europeu. www.nucleotrabalhistacalvet.com.br <http://www.nucleotrabalhistacalvet.com.br/artigos/ Flexiseguran\%C3\%A7a\%20-\%20Jos\%C3\%A9\%20Affonso\%20Dallegrave\%20Neto.pdf>. Acesso em 05 out. 2012.

${ }^{26}$ RODRÍGUEZ, Jesús Baz. El Marco Jurídico Comunitário del Trabajo a Tiempo Parcial. Reflexiones em el Contexto de la "flexiseguridad". In: Trabajo a Tiempo Parcial y Flexiseguridad. RODRÍGUEZ, Jesús Baz (Org.). Granada: Comares, 2008, p. 5 e 10-11.
} 
A flexibilização dos direitos trabalhistas na Comunidade Europeia possui noção indeterminada, altamente difusa e multidirecional, forjada a partir de uma combinação transacionada de elementos políticos ideológicos e aderências tanto liberais como socialdemocratas. Essas características refletem na heterogeneidade da sua regulamentação nos países da Comunidade Europeia. ${ }^{27}$

Tendo por freio o princípio da proteção do trabalhador, a flexibilização das normas trabalhistas requer muita razoabilidade e a ideia espanhola de "flexiseguridad" procura justamente combinar as aspirações empresariais de alternativas de maior flexibilidade dos direitos dos empregados, sem retirar os direitos trabalhistas constitucionalizados pelos países membros da Comunidade Europeia.

Nesse contexto, surge o trabalho a tempo parcial com grande utilização na Comunidade Europeia, também chamado de part time servisse, sendo principalmente adotado em relação ao trabalho de mulheres, idosos e estudantes,

${ }^{27}$ RODRíGUEZ, Jesús Baz. El Marco Jurídico Comunitário del Trabajo a Tiempo Parcial. Reflexiones em el Contexto de la "flexiseguridad". In: Trabajo a Tiempo Parcial y Flexiseguridad. RODRÍGUEZ, Jesús Baz (Org.). Granada: Comares, 2008, p. 8 e 9; No Brasil a flexibilização dos direitos trabalhistas foi iniciada há muito tempo, em 1967, com a troca da estabilidade pelo FGTS. Conforme Jorge Luiz Souto Maior "várias iniciativas se seguiram nesta linha: a) em 1974, após não se renovar a assinatura da Convenção 96 da OIT, admitiu-se o trabalho temporário; b) em 1977, os estagiários deixaram de ser considerados empregados, para serem afastados da proteção da legislação trabalhista; c) em 1983, regulamentou-se o trabalho de vigilância, para excluir os vigilantes do benefício da jornada reduzida de 6 horas destinada ao setor bancário; f) em 1993, a jurisprudência do Tribunal Superior do Trabalho foi radicalmente alterada (originando a Súmula $n^{\circ}$ 331) para, mesmo sem uma autorização legal, considerar possível a elaboração de um contrato entre empresas para prestação de serviço no estabelecimento da empresa "tomadora" da mão-de-obra. [...]; d) em 1998, tentou-se alargar as possibilidades de concluir contratos com duração determinada. A lei criou um novo tipo de contrato, denominado 'contrato provisório'. De acordo com a lei, passou a ser possível a formação de um contrato por prazo determinado, sem vinculação a qualquer motivo específico, a não ser o fato de estar previsto em um instrumento coletivo e ser destinado ao aumento do número de empregados da empresa; e) em 1998, flexibilizaram-se ainda mais os limites da jornada de trabalho pela criação do chamado "de banco de horas". De acordo com este sistema, as horas suplementares podem ser compensadas dentro do período de um ano, sem nenhum pagamento adicional; f) em 1999, foi criado o contrato a tempo parcial, embora na realidade, seja pouco utilizado devido ao baixo nível do salário dos empregados a tempo completo. Nesta linha de "flexibilização" situam-se também decisões judiciais que consideram possível a supressão de direitos previstos na lei por meio de acordos e convenções coletivas de trabalho" (MAIOR, Jorge Luiz Souto. Opinião pública e Direito do Trabalho: tentando transpor as barreiras da comunicação. Justiça do Trabalho. Porto Alegre: HS Editora, v. 286, p. 31-32, out. 2007). Além disso, a Constituição Federal de 1988, adotou, em limitadas hipóteses, a relativização de importantes direitos trabalhistas, mas em todos os casos requer previsão em acordo ou convenção coletiva (a chamada tutela sindical): art. $7^{\circ}, \mathrm{XIII}$ e XIV, que dispõe sobre a jornada de trabalho e sobre turnos de revezamento e art. $7^{\circ}$, VI que excepciona o princípio da irredutibilidade salarial. Note-se que a Consolidação das Leis do Trabalho (publicada originalmente em 1943) já autorizava a flexibilização de direitos trabalhistas principalmente em casos de jornada de trabalho de profissões regulamentadas um tratamento excepcional, via acordo ou convenção coletiva. Exemplificando vejam-se os seguintes dispositivos consolidados: artigos 227, $\S 2^{\circ} ; 235$; Para hipóteses de flexibilização aplicáveis para todas profissões ver os seguintes artigos da CLT: 58, § $3^{\circ} ; 59$ e $\S 2^{\circ} ; 143$, § $2^{\circ} ; 413$, I; 462; 476-A. 
muitas vezes impossibilitados de cumprir um contrato de trabalho de jornada integral, em razão das responsabilidades familiares e profissão que precisam ser conciliadas ${ }^{28}$.

Ainda que tenha os seus problemas, que serão destacados no item 5 infra, o contrato de trabalho a tempo parcial tem se constituído em um dos importantes instrumentos que procuram responder as necessidades de flexibilidade reclamada pela política de emprego comunitária ${ }^{29}$.

\section{O ACORDO MARCO EUROPEU EM MATÉRIA DE TRABALHO A TEMPO PARCIAL RECONHECIDO PELA DIRETIVA 97/81/CE (1997) - DEFINIÇÕES E PRINCÍPIOS}

A União Europeia posicionou-se de maneira expressa sobre a necessidade de encontrar novos caminhos para as relações de trabalho a partir do da Diretiva 97/81/CE (1997).

Mediante interessante comparação entre a regulação do trabalho a tempo parcial na Espanha e na Alemanha (Lei federal de 21 de dezembro de 2000 - Gesetz über Teilzeitarbeit und befristete Arbeitsverträge), Alberto Arufe Varela $^{30}$ defende que ambas possuem grandes semelhanças, inclusive com alguns clones, o que se justifica por tratar-se de normas que regulamentam internamente as imposições da Diretiva Comunitária 97/81/CE (1997), todavia ressalva que possuem importantes diferenças quanto a sua concepção e quanto ao seu conteúdo.

De uma forma, a regulação interna espanhola concebe o trabalho a tempo parcial como uma modalidade odiosa de contrato de trabalho e a prova disso está especialmente pelo fato de que o artigo 12 do Estatuto de los Trabajadores dedica uma atenção preferencial (no item 5) a possibilidade de aumentar a jornada, caso queira o empresário, através da horas complementares. De outra forma, a regulação interna alemã concebe o trabalho a tempo parcial como um fenômeno normal e cobre especificamente a "redução da jornada de trabalho (Verringerung der Arbeitszeit), que como seu próprio nome indica a

\footnotetext{
${ }^{28}$ ARAÚJO, Gisele Ferreira de. Flexibilização do Direito Laboral e a Constituição Federal de 1988. Justiça do Trabalho. Porto Alegre: HS Editora, v. 262, p. 9, out. 2005; Para um estudo do trabalho a tempo parcial como instrumento conciliação da vida familiar e laboral, no Direito Espanhol, destacando que as políticas de tal conciliação não são exclusivas das mulheres, mas exigências das sociedades modernas, independentemente do sexo de seus destinatários, ver: MORGADO PANADERO, Purificación. El Trabajo a Tiempo Parcial como Conciliación de la Vida Familiar e Laboral. In: Trabajo a Tiempo Parcial y Flexiseguridad. RODRíGUEZ, Jesús Baz (Org.). Granada: Comares, p. 85-121, 2008.

${ }^{29}$ MARTíN HERNÁNDEZ, María Luisa. La Protección Social de los Trabajadores a Tiempo Parcial em el Nuevo Marco de la Flexiseguridad. In: Trabajo a Tiempo Parcial y Flexiseguridad. RODRíGUEZ, Jesús Baz (Org.). Granada: Comares, 2008, p. 151.

${ }^{30}$ VARELA, Alberto Arufe. La Regulación de los Contratos de Trabajo a Tiempo Parcial y a Plazo en Alemania. Estudio comparativo con la regulación de los contratos precarios en España. Anuario da Facultade de Dereito da Universidade da Coruña, no ${ }^{\circ} 11$, p. 71-80, em especial, p. 75, 2007.
} 
possibilidade que se outorga ao trabalhador de exigir que sua jornada contratualmente pactuada se reduza, apenas se reduza ${ }^{31}$.

Os objetivos da modalidade contratual do trabalho a tempo parcial por um lado não limitam-se apenas a mera redução da jornada, mas também a flexibilização da prestação do trabalho (poder diretivo do empregador) e, por outro lado, (em relação ao empregado), podem proporcionar a compatibilização do tempo destinado ao trabalho com outras prioridades vitais dos trabalhadores, tais como vida familiar, estudos, outras ocupações profissionais, etc. ${ }^{32}$

Para efeitos desse acordo da Comunidade Europeia, entende-se por trabalhador a tempo parcial o assalariado cujo tempo normal de trabalho, calculado numa base semanal ou como média ao longo de um período de emprego até um ano, é inferior ao tempo normal de trabalho de um trabalhador comparável a tempo inteiro. Trabalhador comparável a tempo inteiro significa um trabalhador a tempo inteiro do mesmo estabelecimento, com o mesmo contrato ou relação de emprego e que exerça funções iguais ou semelhantes, tendo em conta outros fatores, como antiguidade, qualificações, conhecimentos, etc. Se no estabelecimento não houver qualquer trabalhador comparável a tempo inteiro, a comparação será efetuada em consonância com a convenção coletiva aplicável ou, na ausência desta, em conformidade com a legislação, as convenções coletivas ou as práticas vigentes a nível nacional. ${ }^{33}$

\footnotetext{
${ }^{31}$ VARELA, Alberto Arufe. La Regulación de los Contratos de Trabajo a Tiempo Parcial y a plazo en Alemania. Estudio comparativo con la regulación de los contratos precarios en España. Anuario da Facultade de Dereito da Universidade da Coruña, n 11, p. 71-80, em especial, p. 75, 2007.

32 RODRÍGUEZ, Jesús Baz. El Marco Jurídico Comunitário del Trabajo a Tiempo Parcial. Reflexiones em el Contexto de la "flexiseguridad". In: Trabajo a Tiempo Parcial y Flexiseguridad. RODRÍGUEZ, Jesús Baz (Org.). Granada: Comares, 2008, p. 9; MARTíN HERNÁNDEZ, María Luisa. La Protección Social de los Trabajadores a Tiempo Parcial em el Nuevo Marco de la Flexiseguridad. In: Trabajo a Tiempo Parcial y Flexiseguridad. RODRÍGUEZ, Jesús Baz (Org.). Granada: Comares, 2008, p. 161.

${ }_{33}$ Conforme a cláusula 3, itens 1 e 2, da Diretiva 97/81/CE do Conselho da União Europeia, de 15.12.1997; No Brasil, a Medida Provisória no 2164-41/2001 introduziu o art. 58-A na CLT instituindo o regime de tempo parcial, considerado como aquele cuja duração não exceda a vinte e cinco horas semanais, mediante pagamento de salário proporcional a sua jornada, em relação aos empregados que cumprem, nas mesmas funções, tempo integral ( $\S 1^{\circ}{ }^{\circ}$, do art. 58-A da CLT). Esse sistema exige previsão em instrumento decorrente de negociação coletiva ( $\S 2^{\circ}$, do art. 58-A da CLT). O empregado sujeito a tempo parcial não poderá prestar horas extras (art. 59, par. $4^{\circ}$, da CLT), salvo as situações excepcionais previstas no art. 61 da CLT (em face de motivo de força maior, seja para atender à realização ou conclusão de serviços inadiáveis ou cuja inexecução possa acarretar prejuízo manifesto). O empregado contratado sob o regime de tempo parcial terá direito a férias após cada período de doze meses de vigência do contrato de trabalho, o empregado terá direito a férias, após cada período de doze meses de vigência do contrato de trabalho, na proporção prevista no art. 130-A da CLT, conforme a sua duração de trabalho semanal. Aos empregados sob o regime de tempo parcial não se aplica a faculdade de converter 1/3 (um terço) do período de férias a que tiver direito em abono pecuniário, no valor da remuneração que the seria devida nos dias correspondentes, em face de expressa previsão contida no parágrafo $3^{\circ}$ do art. 143 da CLT. Esse regime de trabalho efetivamente não "pegou" no Brasil, mas continua vigente e pode ser utilizado.
} 
Um dos princípios destacados pela Diretiva 97/81/CE é o princípio da não discriminação em relação às formas de emprego típica com jornada completa: no que respeitam às condições de emprego, os trabalhadores a tempo parcial não devem ser tratados em condições menos favoráveis do que os trabalhadores comparáveis a tempo inteiro unicamente pelo fato de trabalharem a tempo parcial, a menos que, por razões objetivas, a diferença de tratamento se justifique. ${ }^{34}$

Outro princípio considerado vertebral no texto comunitário é o princípio da voluntariedade: a conversão de um trabalho a tempo completo em um trabalho a tempo parcial e vice-versa terá sempre caráter voluntário para o trabalhador e não se poderá impor de forma unilateral e o trabalhador não poderá ser despedido nem sofrer nenhum outro tipo de sanção ou prejuízo apenas por ele não aceitar a conversão, sem prejuízo da possibilidade de, nos termos da legislação, das convenções coletivas ou das práticas nacionais, proceder a despedimentos por outras razões, como as que podem resultar de contingências de funcionamento do estabelecimento em causa. ${ }^{35}$

Cabe destacar ainda o princípio da proporcionalidade (princípio pro rata temporis), segundo o qual os trabalhadores a tempo parcial terão os mesmos direitos que os trabalhadores a tempo completo, de acordo com o tempo proporcionalmente trabalhado em comparação com o trabalho a tempo completo. ${ }^{36}$

As principais críticas formalizadas por Rodríguez ${ }^{37}$ a diretriz comunitária (Diretiva 97/81/CE) são: a) há necessidade de se encontrar novos equilíbrios entre a lógica econômica e a lógica social e da mesma forma entre flexibilidade e segurança, sendo que a estratégia europeia para o emprego omitiu-se sobre a necessidade de se impulsionar reformas em outros âmbitos; b) os documentos comunitários iniciadores deste processo além de ter ignorado clamorosamente toda referência aos direitos sociais fundamentais inerentes ao constitucionalismo social reconhecidos tanto no âmbito comunitário como nas experiências nacionais, se conformam com efetuar indicações sumamente não concretas, que oscilam o etéreo princípio ordenador da "flexiseguridad"; c) o critério de adequação dos países membros ${ }^{38}$ abre margem de discricionariedade tanto para o legislador como para a autonomia coletiva.

${ }^{34}$ Conforme a cláusula 4, item 1, da Diretiva 97/81/CE do Conselho da União Européia, de 15.12.1997.

${ }^{35}$ Conforme a cláusula 5, item 2, da Diretiva 97/81/CE do Conselho da União Européia, de 15.12.1997.

${ }^{36}$ Conforme a cláusula 4, item 2, da Diretiva 97/81/CE do Conselho da União Européia, de 15.12.1997.

37 RODRíGUEZ, Jesús Baz. El Marco Jurídico Comunitário del Trabajo a Tiempo Parcial. Reflexiones em el Contexto de la "flexiseguridad". In: Trabajo a Tiempo Parcial y Flexiseguridad. RODRÍGUEZ, Jesús Baz (Org.). Granada: Comares, 2008, p. 6-7 e 28.

${ }^{38}$ Conforme a cláusula 4, item 2, da Diretiva 97/81/CE do Conselho da União Européia, de 15.12.1997. 
Um dos cuidados necessários na implantação interna da flexisegurança e dos seus instrumentos - como o trabalho a tempo parcial - está no receio de dumping social. E o caminho apontado para que se evite essa mazela está no diálogo entre os interlocutores sociais. ${ }^{39}$

\section{A NOÇÃO DE TRABALHO A TEMPO PARCIAL NO DIREITO ESPANHOL - ANÁLISE CRÍTICA}

O Estatuto de los Trabajadores - Real Decreto Ley 1/1995, prevê no artigo 12, introduzido pelo RDL 15/1998 e alterado pelo RDL 3/2012, as principais características do trabalho a tempo parcial no Direito Espanhol: a) por escrito, necessariamente; b) prestação de serviços durante um número de horas ao dia, na semana, ao mês ou ao ano inferior a $77 \%$ da jornada a tempo completo ${ }^{40}$; c) poderá ser por tempo indefinido ou por duração determinada. ${ }^{41}$ Se entenderá celebrado por tempo indefinido quando: c.1) firmado para realizar trabalhos fixos e periódicos dentro do volume normal de atividade da empresa; c.2) firmado para realizar trabalhos que tenham caráter de fixos-descontínuos e no se repitam em períodos certos; a jornada diária poderá realizar-se de forma continuada ou fracionada (caso em que só será possível efetuar una única interrupção, salvo que se disponha diferentemente mediante convênio coletivo); d) os trabalhadores a tempo parcial terão os mesmos direitos que os trabalhadores a tempo completo ${ }^{42}$; e) é permitida a realização de horas extraordinárias cujo número será o legalmente previsto em proporção a jornada pactuada; f) a conversão de um trabalho a tempo completo em um trabalho a tempo parcial e vice-versa terá sempre caráter voluntario para os trabalhadores não se poderá impor de forma unilateral e o trabalhador não poderá ser despedido nem sofrer nenhum outro tipo de sanção ou prejuízo por não aceitar a conversão, sem prejuízo das medidas que, de conformidade com o disposto nos artigos 51 e 52 do Estatuto de los Trabajadores, possam ser adotadas em face de causas econômicas, técnicas, organizativas ou de produção.

39 RODRíGUEZ, Jesús Baz. El Marco Jurídico Comunitário del Trabajo a Tiempo Parcial. Reflexiones em el Contexto de la "flexiseguridad". In: Trabajo a Tiempo Parcial y Flexiseguridad. RODRÍGUEZ, Jesús Baz (Org.). Granada: Comares, 2008, p. 16.

${ }^{40} \mathrm{~A}$ jornada a tempo completo na Espanha é de no máximo 40 horas semanais.

${ }^{41}$ Lembra-se que o período de prova na Espanha (contrato de experiência) não pode ser superior a 6 meses para os técnicos titulados, a 3 meses para os trabalhadores em empresas de menos de 25 trabalhadores e a 2 meses para o resto dos trabalhadores, conforme o disposto no artigo 14 do Estatuto de los Trabajadores.

${ }^{42}$ Art. 12.4. "d" do ET: "“'Los trabajadores a tiempo parcial tendrán los mismos derechos que los trabajadores a tiempo completo. Cuando corresponda em atención a su naturaleza, tales derecho sserán reconocidos em lãs disposiciones legales y reglamentarias y em los Convenios Colectivos de manera proporcional, enfunción del tiempo trabajado"; Tejedor sustenta que este dispositivo legal contém clara restrição a autonomia individual da vontade, conforme TEJEDOR, José Antonio Baz. El Principio de Igualdad, no Discriminación (y proporcionalidad) en el Trabajo a Tiempo Parcial. In: Trabajo a Tiempo Parcial y Flexiseguridad. RODRÍGUEZ, Jesús Baz (Org.). Granada: Comares, 2008, p. 80. 
Acerca da possibilidade de redução das horas de trabalho por razões econômicas, técnicas, organizacionais ou produção, Carmen Ferradans Caramés ${ }^{43}$ esclarece ser uma das medidas de flexibilidade interna promovidas pelo Real Decreto Ley 10/2010, de 16 de junho, que alterou o artigo 47.2 do Estatuto de los Trabajadores, objetivando conservar o emprego dos trabalhadores que estão no mercado de trabalho, mantendo a empresa seu pessoal qualificado.

Ressalta a autora $^{44}$, que a diferença em relação à regra geral da modalidade contratual por prazo indeterminado está essencialmente nas bonificações das cotas empresariais para com a Seguridade Social e no direito a reposição da prestação por desemprego, impulsionares dessa medida. Conclui que a redução temporária da jornada de trabalho, como medida de ajuste do emprego em situações de crises, é uma ferramenta positiva, não obstante resta pendente a maior agilidade de seu procedimento nos casos em que sejam afetados poucos trabalhadores, pois do contrário será pouco utilizada.

Todo o esforço conciliatório de nada adiantará se empregados e empregadores não cumprirem efetivamente as normas diferenciadas dessa modalidade atípica de contrato de trabalho. Com essa preocupação, Benavente Torres $^{45}$ reclama que se exija um firme compromisso obrigacional das partes optantes do trabalho a tempo parcial, a recuperação de equilíbrio contratual (insatisfeito com a mera aplicação do princípio da proporcionalidade) e uma resposta contundente dos Tribunais aos descumprimentos contratuais da jornada de trabalho diferenciada nessa modalidade contratual.

Analisando a legislação sobre trabalho a tempo parcial existente na Espanha (art. 12 do ET, acima reproduzido), Rodriguez tece as seguintes críticas: a) não the parece acertado o legislador espanhol ter assumido literalmente a definição da norma comunitária, pois dessa forma não se observaram as peculiaridades espanholas; b) sustenta que, na aplicação do direito trabalhista espanhol, por vezes há confusão entre várias modalidades contratuais existentes $^{46}$ e que isso atrapalha a adequada utilização do trabalho a tempo parcial; c) destaca a revitalização da atuação jurisdicional protetora ao apreciar discriminação indireta por razão de sexo das trabalhadoras a tempo parcial; d) destaca o papel transcendental da negociação coletiva, tanto no contexto comunitário quanto no espanhol, para a verificação das razões

\footnotetext{
${ }^{43}$ CARAMĖS, Carmen Ferradans. La Reducción de la Jornada de Trabajo como Mecanismo de Reestructuración Empresarial frente a las Crisis de Empleo. Rev. Temas Laborales. Sevilha: Consejo Andaluz Relac. Laborales. $n^{\circ}$ 107, p. 227-264, em especial, p. 243, 263-264, 2010.

${ }^{44}$ CARAMĖS, Carmen Ferradans. La Reducción de la Jornada de Trabajo como Mecanismo de Reestructuración Empresarial frente a las Crisis de Empleo. Rev. Temas Laborales. Sevilha: Consejo Andaluz Relac. Laborales. $n^{\circ}$ 107, p. 227-264, em especial, p. 243, 263-264, 2010.

${ }^{45}$ BENAVENTE TORRES, Maria Immaculada. El Trabajo a Tiempo Parcial. Sevilha: Consejo Económico y Social de Andalucía, 2005.

${ }^{46}$ Arts. 10 a 13 do Estatuto de los Trabajadores.
} 
objetivas que podem autorizar tratamentos diferenciados, não discriminatório do trabalho a tempo parcial, como autêntica peça de ajuste na busca da "flexiseguridad"47; e) esclarece que o legislador espanhol tem buscado desesperadamente aumentar os índices quantitativos de emprego, recorrendo a esta modalidade de contratação; f) defende que a negociação coletiva não poderá delimitar conceitualmente essa modalidade contratual, restringindo o âmbito de aplicação da norma; g) prega a harmonização (afirma que o método clássico de harmonização das legislações laborais internas está esclerosado), a coordenação (sustenta a substituição das técnicas de hard law por uma metodologia de coordenação menos vinculante e mais voluntarista - soft law, amparada por interpretações extensivas dos princípios comunitários de subsidiariedade e proporcionalidade) e a atuação coletiva em matéria de trabalho a tempo parcial, por meio dos interlocutores sociais, para efetivação da "flexiseguridad". ${ }^{48}$

Martín Hernández acrescenta que se deve mudar a maneira de pensar a proteção dos trabalhadores a tempo parcial fixando a atenção não tanto em suas diferenças técnicas em relação ao trabalho a tempo completo: sugere a autora que deixe-se de considerar o princípio da proporcionalidade como critério absoluto central e essencial do desenho do regime de proteção aplicável aos trabalhadores a tempo parcial. Essa mudança de ótica implicaria a adoção de medidas que ultrapassem a mera equiparação formal entre trabalhadores a tempo completo e que tenderão a igualdade real e efetiva de uns e outros. ${ }^{49}$ Frise-se o ponto: A igualdade formal não é suficiente. ${ }^{50}$

\section{CONSIDERAÇÕES FINAIS}

O histórico de altos índices de desemprego na Espanha foi acentuado pelos desdobramentos da crise financeira internacional ocorrida em 2008, marcada pela falência do tradicional banco de investimento estadunidense Lehman Brothers, no qual, em efeito dominó, outras grandes instituições financeiras "quebraram", no processo também conhecido como crise dos subprimes ou grande recessão. Todavia, os Direitos Sociais, e mais

\footnotetext{
${ }^{47}$ Morato García adverte que a observação do panorama negocial atual revela, todavia, que são poucos os convênios coletivos que contempla a contratação de trabalho fixo descontínuo de execução incerta ou irregular com o devido esmero e previsão (MORATO GARCíA, Rosa Maria. Contratación Fija-discontínua de Carácter Irregular y la Reincorporación al Trabajo. In: Trabajo a Tiempo Parcial y Flexiseguridad. RODRÍGUEZ, Jesús Baz (Org.). Granada: Comares, 2008, p. 149). 48 RODRÍGUEZ, Jesús Baz. El Marco Jurídico Comunitário del Trabajo a Tiempo Parcial. Reflexiones em el Contexto de la "flexiseguridad". In: Trabajo a Tiempo Parcial y Flexiseguridad. RODRíGUEZ, Jesús Baz (Org.). Granada: Comares, 2008, p. 23-24, 26, 28 e 33, 29, 30, 34-35, respectivamente.

49 MARTín HERNÁNDEZ, María Luisa. La Protección Social de los Trabajadores a Tiempo Parcial em el Nuevo Marco de la Flexiseguridad. In: Trabajo a Tiempo Parcial y Flexiseguridad. RODRÍGUEZ, Jesús Baz (Org.). Granada: Comares, 2008, p. 184.

50 MARTíN HERNÁNDEZ, María Luisa. La Protección Social de los Trabajadores a Tiempo Parcial em el Nuevo Marco de la Flexiseguridad. In: Trabajo a Tiempo Parcial y Flexiseguridad. RODRÍGUEZ, Jesús Baz (Org.). Granada: Comares, 2008, p. 181.
} 
especificamente os dos trabalhadores, não podem ser reduzidos a uma questão de custo. ${ }^{51}$ Essa premissa é fundamental para que não se caminhe para uma perigosa parente próxima da flexibilização: a desregulamentação dos direitos trabalhistas ${ }^{52}$.

Nesse contexto, a situação econômica e social espanhola é realmente grave e o trabalho a tempo parcial aparece como um dos instrumentos da "flexiseguridad" e uma das poucas alternativas até então apresentadas para enfrentar essa imensa problemática. Ocorre que, em face desse contexto atual, o trabalho a tempo parcial tem sido utilizado na Espanha em forma bastante superior ao que seria adequado (tanto em quantidade, como em finalidades), pois ainda que seja uma modalidade contratual válida para inserção no mercado de trabalho de jovens, por exemplo, sua utilização predominante está longe de ser o ideal para todos envolvidos (trabalhadores, empregadores e o próprio país) e revela a precarização do trabalho ${ }^{53}$, pois quanto menor a jornada, menor é o salário (proporcionalmente ao tempo trabalhado), diminuindo a renda das famílias que possuem trabalhadores nessa modalidade contratual, sem falar nas modalidades informais de trabalho onde a precarização é ainda maior. ${ }^{54}$

Uma crise da grandeza da que passa a Espanha, entre outros países da Europa, não se resolve com medidas isoladas, mas necessita um conjunto de medidas e de mudanças efetivas (culturais, inclusive), que não se processam "da noite para o dia".

O caminho para essa situação complexa também é complexo e difícil, mas não é novo: está na harmonização entre o capital e o trabalho (ou entre o social e o econômico numa roupagem mais abrangente), "segundo a qual a finalidade protetora combina-se com a coordenação dos interesses entre o capital e o trabalho". ${ }^{55} \mathrm{Em}$ verdade, essa necessidade recíproca já era

\footnotetext{
${ }^{51}$ MAIOR, Jorge Luiz Souto. O Dano Social e sua Reparação. Justiça do Trabalho. Porto Alegre: HS Editora, no 288, p. 10, dez. 2007.

${ }^{52}$ MARTín HERNÁNDEZ, María Luisa. La Protección Social de los Trabajadores a Tiempo Parcial em el Nuevo Marco de la Flexiseguridad. In: Trabajo a Tiempo Parcial y Flexiseguridad. RODRÍGUEZ, Jesús Baz (Org.). Granada: Comares, 2008, p. 161-162.

53 "A precariedade, embora não seja um atributo da flexibilidade, pode conduzir a precarização" (BARROS JR, Cássio de Mesquita. Flexibilização do Direito do Trabalho. Revista LTr. São Paulo: LTr, v. São Paulo: LTr, ano 59, no 8, p. 1035, ago. 1995).

${ }^{54}$ Essa modalidade de contrato "tenta evitar a elevação das altas taxas de desemprego no mundo", conforme ARAÚJO, Gisele Ferreira de. Flexibilização do Direito Laboral e a Constituição Federal de 1988. Justiça do Trabalho. Porto Alegre: HS Editora, v. 262, p. 9, out. 2005; Tratando da precarização no Direito Espanhol, Morato García afirma que tem existido um crescente interesse por regulamentar apaixonadamente as peculiaridades da contratação de trabalho fixo descontínuo de execução incerta ou irregular, fruto das oscilações do mercado que se repetem em ciclos conjunturais (MORATO GARCíA, Rosa Maria. Contratación Fija-discontínua de Carácter Irregular y Lareincorporación al Trabajo. In: Trabajo a Tiempo Parcial y Flexiseguridad. RODRÍGUEZ, Jesús Baz (Org.). Granada: Comares, 2008, p. 149).

${ }^{55}$ NASCIMENTO, Amauri Mascaro. Direito Contemporâneo do Trabalho. São Paulo: LTr, 2011, p. 37; Adverte Romagnoli que a ameaça mais séria contra a qual o Direito do Trabalho deverá
} 
salientada em 1891, pelo Papa Leão XIII, na famosa carta encíclica Rerum Novarum (Coisas Novas): sobre a condição dos trabalhadores, de que "não pode haver capital sem trabalho, nem trabalho sem capital". ${ }^{56}$

Trata-se de umas equações de mais difícil conciliação em face da complexidade de fatores que a envolvem, mas o seu enfrentamento efetivo é de vital importância não apenas para os países que passam por tais problemas como o da Espanha, mas por todos os países, em face da globalização. Em situações graves como essa é comum haver maior cedência de posicionamentos, estando aí uma ótima oportunidade para que haja efetivamente o necessário diálogo entre os interlocutores sociais e medidas efetivas e não o contrário como fez recentemente a Espanha, por meio do Real Decreto-ley 3/2012, ao limitar a atuação da negociação coletiva.

\section{REFERÊNCIAS}

ARAÚJO, Gisele Ferreira de. Flexibilização do Direito Laboral e a Constituição Federal de 1988. Justiça do Trabalho. Porto Alegre: HS Editora, v. 262, p. 8-23, out. 2005.

BAGLIONI, Guido. O Mundo do Trabalho - Crise e mudança no final do século. São Paulo: Scritta, 1994.

BARROS JR, Cássio de Mesquita. Flexibilização do Direito do Trabalho. Revista $L T r$. São Paulo: LTr, v. São Paulo: LTr, ano 59, no 8, p. 1034-1035, ago. 1995.

BENAVENTE TORRES, Maria Immaculada. El Trabajo a Tiempo Parcial. Sevilha: Consejo Económico y Social de Andalucía, 2005.

COIMBRA, Rodrigo; ARAÚJO, Francisco Rossal de. Direito do Trabalho: evolução do modelo normativo e tendências atuais na Europa. Revista LTr. São Paulo: LTr, ano 73, t. II, no 08, p. 953-962, ago. 2009.

CARAMĖS, Carmen Ferradans. La Reducción de la Jornada de Trabajo como Mecanismo de Reestructuración Empresarial frente a las Crisis de Empleo. Rev. Temas Laborales. Sevilha: Consejo Andaluz Relac. Laborales. nº 107, p. 227-264, 2010.

DALLEGRAVE NETO, José Affonso. Flexisegurança nas Relações de Trabalho. O Novo Debate Europeu. www.nucleotrabalhistacalvet.com.br <http://www.nucleotrabalhistacalvet. com.br/artigos/Flexiseguran\%C3\%A7a\%20-\%20Jos\%C3\%A9\%20Affonso\%20Dallegrave \%20Neto.pdf>. Acesso em 05 out. 2012.

defender-se "é a desintegração ao contato com um mundo da produção extremadamente diversificado em uma pluralidade de interesses que se negam a adequar-se a lógica de harmonização" (ROMAGNOLI, Umberto. El Derecho del Trabajo: Qué Futuro?. In Evolucion del Pensamento Juslaboralista. Montevideo: Fundacion de Cultura Universitária, 1997, p. 437).

${ }^{56}$ LEÃO XIII. Carta encíclica "Rerum Novarum" sobre a condição dos operários. www.vatican.va. $<$ http://uww.vatican.va/holy_father/leo_xiii/encyclicals/documents/hf_l-xiii_enc_15051891_rerum-novarum _po.html>. Acesso em 22 nov. 2011: [...] "O erro capital na questão presente é crer que as duas classes são inimigas natas uma da outra, como se a natureza tivesse armado os ricos e os pobres para se combaterem mutuamente num duelo obstinado. Isto é uma aberração tal, que é necessário colocar a verdade numa doutrina contrariamente oposta, porque, assim como no corpo humano os membros, apesar da sua diversidade, se adaptam maravilhosamente uns aos outros, de modo que formam um todo exactamente proporcionado e que se poderá chamar simétrico, assim também, na sociedade, as duas classes estão destinadas pela natureza a unirem-se harmoniosamente e a conservarem-se mutuamente em perfeito equilíbrio. Elas têm imperiosa necessidade uma da outra: não pode haver capital sem trabalho, nem trabalho sem capital" [...]. 
DEZALAY, Ives; TRUBEK, David M. A Reestruturação Global e o Direito. In: Direito e Globalização Econômica: implicações e perspectivas. José Eduardo Faria (Org.). São Paulo: Malheiros, 1998.

DE MASI, Domenico. O Futuro do Trabalho: fadiga e ócio na sociedade pós industrial. 5. ed., Brasília: Unb, 2000.

ERRAZURIZ, Francisco Walker. La Flexibildad Laboral y los Princípios Orientadores del Derecho del Trabajo, teniendo em cuenta, em forma particular, algunos aspectos de la Legislación Chilena. In: Evolucion del Pensamento Juslaboralista. Montevideo: Fundacion de Cultura Universitária, 1997.

FILAS, Rodolfo Capón. Trabajo y Globalizacion Propuesta para una Praxis Popular Alternativa. Justiça do Trabalho. Porto Alegre: HS Editora, ano 18, n 205, p. 7-26, jan. 2001.

FINCATO, Denise Pires. A Pesquisa Jurídica sem Mistérios: do projeto de pesquisa à banca. Porto Alegre: Notadez, 2008.

FRIEDMAN, Thomas L. O Mundo é Plano: o mundo globalizado no século XXI. 3. ed., Rio de Janeiro: Objetiva, 2009.

LEÃO XIII. Carta Encíclica "Rerum Novarum" sobre a condição dos operários. www.vatican.va. <http://www.vatican.va/holy_father/leo_xiii/encyclicals/documents/hf_l-xiii_ enc_15051891_rerum-novarum_po.html>. Acesso em 22 nov. 2011.

LYON-CAEN, Gerard. Derecho del Trabajo o Derecho del Emprego?. In: Evolucion del Pensamento Juslaboralista. Montevideo: Fundacion de Cultura Universitária, 1997.

MAIOR, Jorge Luiz Souto. O Dano Social e sua Reparação. Justiça do Trabalho. Porto Alegre: HS Editora, nº 288, p. 6-18, dez. 2007.

. Opinião Pública e Direito do Trabalho: tentando transpor as barreiras da comunicação. Justiça do Trabalho. Porto Alegre: HS Editora, v. 286, p. 24-36, out. 2007. MARTÍN HERNÁNDEZ, María Luisa. La Protección Social de los Trabajadores a Tiempo Parcial em el Nuevo Marco de la Flexiseguridad. In: Trabajo a Tiempo Parcial y Flexiseguridad. RODRÍGUEZ, Jesús Baz (Org.). Granada: Comares, 2008.

MEZZAROBA, Orides; MONTEIRO, Cláudia Servilha. Manual de Metodologia da Pesquisa no Direito. 3. ed., São Paulo: Saraiva, 2006.

MORATO GARCÍA, Rosa Maria. Contratación Fija-discontínua de Carácter Irregular y la Reincorporación al Trabajo. In: Trabajo a Tiempo Parcial y Flexiseguridad. RODRÍGUEZ, JesúsBaz (Org.). Granada: Comares, 2008.

MORGADO PANADERO, Purificación. El Trabajo a Tiempo Parcial como Conciliación de la Vida Familiar e Laboral. In: Trabajo a Tiempo Parcial y Flexiseguridad. RODRÍGUEZ, Jesús Baz (Org.). Granada: Comares, 2008.

NASCIMENTO, Amauri Mascaro. Direito Contemporâneo do Trabalho. São Paulo: LTr, 2011.

ROMITA, Arion Saião. Globalização da Economia e Direito do Trabalho. São Paulo: LTr, 1997.

REALE, Miguel. A Globalização da Economia e o Direito do Trabalho. Revista LTr, São Paulo, v. 61, nº 1, p. 11-13, jan. 1997.

RODRÍGUEZ, Jesús Baz. El Marco Jurídico Comunitário del Trabajo a Tiempo Parcial. Reflexiones en el Contexto de la "flexiseguridad". In: Trabajo a Tiempo Parcial y Flexiseguridad. RODRÍGUEZ, JesúsBaz (Org.). Granada: Comares, 2008. 
ROTH, André-Noel. O Direito em Crise: fim do Estado moderno. In: Direito e Globalização Econômica: implicações e perspectivas. José Eduardo Faria (Org.). São Paulo: Malheiros, 1998.

SANTOS, Boaventura de Souza. Os Processos de Globalização. In: A Globalização e as Ciências Sociais. SANTOS, Boaventura de Souza (Org.). 3. ed., São Paulo: Cortez, 2005.

SUSSEKIND, Arnaldo. et al. Instituições de Direito do Trabalho. V. 1. 20. ed., São Paulo: LTr, 2002.

A Globalização da Economia e o Direito do Trabalho. Revista LTr. São Paulo: LTr, v. 61, p. 41-44, jan. 1997.

TEJEDOR, José Antonio Baz. El Principio de Igualdad, no Discriminación (y proporcionalidad) en el Trabajo a Tiempo Parcial. In: Trabajo a Tiempo Parcial y Flexiseguridad. RODRÍGUEZ, Jesús Baz (Org.). Granada: Comares, 2008.

VAN DER LAAT, Bernardo. Limites a la Flexibildad: algunas situaciones que se han dado em Costa Rica. In: Evolucion del pensamento juslaboralista. Montevideo: Fundacion de Cultura Universitária, 1997.

VARELA, Alberto Arufe. La Regulación de los Contratos de Trabajo a Tiempo Parcial y a Plazo en Alemania. Estudio comparativo con la regulación de los contratos precarios en España. Anuario da Facultade de Dereito da Universidade da Coruña, no 11, p. 71-80, 2007.

VÁSQUEZ, Jorge Rendón. El Caráter Protector del Derecho del Trabajo y la Flexibilidad com Ideologias. In: Evolucion del Pensamento Juslaboralista. Montevideo: Fundacion de Cultura Universitária, 1997. 